\title{
Chiuro laboratory: integration of workflows from digital survey to optimised 3D urban models for interactive exploration
}

\author{
Silvia Bertacchi ${ }^{1} \cdot$ Gianna Bertacchi $^{1}$ (1) $\cdot$ Luca Cipriani $^{1}$ \\ Received: 8 January 2020 / Accepted: 17 December 2020/Published online: 15 January 2021 \\ (C) The Author(s) 2021
}

\begin{abstract}
The digital acquisition of Chiuro (Italy) is part of a research action of the still ongoing project "Le radici di una identità" ("An identity and its roots"), dealing with the documentation of the original urban structure of Chiuro, a small settlement located in northern Italy, whose interesting remains of mediaeval towers and Renaissance palaces are still well preserved. The paper focusses on the complete workflow developed by the group to create an explorative and implementable 3D digital model of the urban centre, constructed by a set of optimised mesh models. From the acquisition phase to geometric processing methodologies, different modelling strategies have been investigated to solve problems related to survey integration, and optimisation of the architectural digital assets. The main challenge is in fact the utilisation of the huge amount of data gathered during the previous surveying campaigns, providing a specific workflow to obtain an optimised 3D model. Moreover, the paper analyses some outputs: one is the storytelling of historical and cultural heritage in an attractive way, using game engines to visualise and give access to detailed digital contents to the general public.
\end{abstract}

Keywords Cultural heritage $\cdot 3$ D models $\cdot$ Digitisation $\cdot$ Procedural modelling $\cdot$ Game engines $\cdot$ Visualisation

\section{Introduction}

Over the last decades, digitisation of cultural assets has become a standard in the documentation process of cultural heritage $(\mathrm{CH})$, and the procedures for data acquisition follow strongly experimented workflows. As these methodologies and techniques become increasingly affordable, reliable and easy to use, accurate 3D reality-based models are a common output of surveying processes. Since surveying campaigns carried out both with terrestrial laser scanner (TLS) and close-range photogrammetry data provide detailed information on shape and colour (Ioannides et al. 2018; Remondino et al. 2018), these digitisation techniques have become a wellestablished process.

Gianna Bertacchi

gianna.bertacchi2@unibo.it

Silvia Bertacchi

silvia.bertacchi@unibo.it

Luca Cipriani

luca.cipriani@unibo.it

1 Department of Architecture, Alma Mater Studiorum-University of Bologna, Bologna, Italy
Scholars are now orienting their research trend in three main topics: (1) specific $\mathrm{CH}$ management tools; (2) automatic or semi-automatic shape generation tools; (3) dissemination and enhancement of $\mathrm{CH}$ through virtual reality devices and game engines.

(1) The first trend investigates tools mainly used by professionals and local authorities. In this case, digital models need to transmit not only shape, metric and colour information, but they are turned into a knowledge and data repository: the 3D model becomes a tool for simultaneous storage and data recall, answering to professional user requirements. This sector is currently split into two main research trends: (1a) Information Systems and webplatforms, and (1b) BIM applications. The choice between one and the other methodology depends mostly on the cultural assets' characteristics, the main aims of the project and the physical and economical resources available. Some examples and latest experimentations are then illustrated:

a) In this category, the most used kinds of 3D modelsbased Information Systems are briefly analysed, with specific references to our research project. The type of system used depends on the scale of the object 
represented. For the urban and archaeological-site scale, 3D Geographical Information Systems provide a useful tool to record and manage the great amount of dispersed information (Apollonio et al. 2012, von Schwerin et al. 2013; Campanaro et al. 2016), often combined with BIM software (Ohori et al. 2017; Matrone et al. 2019; Breunig et al. 2020). For very complex cultural assets an alternative workflow uses 3D-high-detailed-model-based systems (Remondino et al. 2016; Apollonio et al. 2018b). The platform provides the possibility to study, visualise, and add information directly on a high-resolution 3D model, even on-site, in multi-user mode, allowing one to follow the whole data lifecycle related to the specific cultural asset. Latest experimentations are presented in Scopigno and Dellepiane (2017), Soler et al. (2017), Messaoudi et al. (2018), Wang et al. (2018), Apollonio et al. (2019, with a short review of previous bibliography).

b) Building Information Modelling (BIM) solutions are widely experimented and used in the Architecture, Engineering and Construction (AEC) Sector, but the most recent research trend deals with the H-BIM, i.e. the application of BIM solutions to the existing cultural heritage. However, the BIM environment presents criticalities because of its rigidity in modelling non-homologous elements (that constitute most part of an existing building) and it often requires specific plug-ins. Some interesting review and experimentations on the topic can be found in the up-to-date scientific literature (Dore and Murphy 2017; López et al. 2018; Pocobelli et al. 2018; Chiabrando et al. 2018; Bitelli et al. 2019; Banfi 2020).

(2) The second trend topic deals with the research of automatic or semi-automatic shape generation or recognition tools, able to deal with complex architectures and generating models by parametric or procedural 3D modelling. Some experimentations try to provide high-performing and flexible systems, able to easily change in shape and therefore providing multiple reconstructive hypotheses in a quite interactive way (Cipriani and Fantini 2018). Current experimentations deal with the automatic segmentation and classification of point cloud data sources (some examples of the latest and effective algorithms can be checked in Grilli and Remondino 2019) or automatic shape recognition (Poux et al. 2017; Thompson et al. 2018).

(3) The third research orientation concerns the dissemination and enhancement of $\mathrm{CH}$ through virtual reality (VR) devices and game engines. The aim is to use $3 \mathrm{D}$ contents to spread cultural awareness of historical events and heritage assets to a generic public. Immersive VR applications are one of the best tools to involve the public in deepening the knowledge of cultural assets, especially the lesser known but very important for local culture (Fernández-Palacios et al. 2017; Gonizzi Barsanti et al. 2018; Napolitano et al. 2018).

The present contribution proposes a workflow to produce a Set of Optimised Mesh (SOM), of which we analyse creation protocols developed during the ongoing research project. In particular, this first experimentation takes place in the last category introduced in the state-of-the-art overview (3), dealing with the storytelling of historical and cultural contents in an attractive way, using game engines to visualise and give access to detailed digital contents. The main challenge of the project is then not so much the data acquisition, but rather about data unification and compression in a set of optimised meshes. In fact, all geometric and chromatic information from active and passive sensors are gathered together in a low-detail model; regarding compression, it consists of converting geometric and visual information into two typologies of maps, i.e. (i) apparent colour maps where blending frames and (ii) normal maps that compress, although in an apparent way, the geometric detail obtained by sensors (Merlo et al. 2012).

Moreover, the management of huge quantity of data refers to the workflow introduced by Cohen et al. (1998), that is a widely used technique in the field of video game and virtual contents, consisting in encoding normals of high-detail models in the parameter space of low-detail models. This baking process, also known as render-to-texture, necessarily requires the conversion of point clouds from active/passive sensors into triangular polygonal meshes, with semi-automatic procedures (Cipriani and Fantini 2018), but requires special attention to keep under control the deviation between high detail initial models and their simplified low-poly versions.

The case study analysed presents a physical complexity in terms of both spatial extension and the huge amount of data gathered with different surveying methodologies, in different periods of time and by different work teams. Hence the need to follow a specific workflow, oriented in creating the possibility of data multiscale use (both from generic public and professionals). So, the main output of the entire project is focussed on the interactive dissemination of $\mathrm{CH}$ (mainly for generic users), carrying out at the same time some experimentations for producing HBIM models of single principal assets, that answer to professional needs.

The paper is organised as follows: in the "The project" section, the paper deals with the main goals of the project and details on the specific research action carried out by the team; in the "The case study: brief historical introduction" section, the case study is briefly described; the achievement of the explorative 3D model is explained in the "Preliminary experimentations for an explorative model of Chiuro" section, reporting peculiarities and issues of the workflow for each step (sub-sections 3.1: data acquisition, 3.2: modelling workflow, 
3.3: outputs with an example of modelling of a major architectural element); finally in the "Conclusions and future developments" section, conclusions and future developments are set out.

\section{The project}

The 3-year project Le radici di una identità, ${ }^{1}$ started in August 2018 and still ongoing, is a wide applied research project related to the territory intending to rediscover the origins of the Valtellina Cultural District, an area located in northern Italy (province of Sondrio) that boasts centuries of history, with the purpose of studying, protecting and enhancing the region through an in-depth study, in particular of the period from Prehistory to Middle Ages.

The general project focusses on valuable tangible and intangible assets showing the diversity of Valtellina cultural landscapes as a result of complex historical processes and human resilience, and the specific solutions specially developed in that particular area in the medieval period, when the identity of the region was generated and the network of villages - still inhabited today-had settled on the slopes of the mountains.

Assuming that the synergy between the territory (both public and private) and cultural heritage is a driving force for the development of the architectural and artistic heritage, the project fosters the involvement of public and private stakeholders, together with the population, with the aim of the promotion of local development that integrates cultural and social identity, landscapes and traditional productions.

Within this general frame, our team is part of the researchaction on the medieval historical centre of Chiuro (Fig. 1), one of the 19 local administrations located in the Province participating in the RADICI Project, among other partners and stakeholders. $^{2}$

\footnotetext{
${ }^{1}$ Title of the project: Le radici di una identità. Temi, strumenti e itinerari per la (ri)scoperta del mandamento di Sondrio tra Preistoria e Medioevo (An identity and its root. Themes, tools, itineraries for the (re)discovery of the Sondrio district between Prehistory and the Middle Ages). Lead partner: Comunità Montana Valtellina di Sondrio, website: www.cmsondrio.it; Scientific coordinator of the project: Rita Pezzola; Funding: Bando "Emblematici Maggiori” 2017 by Fondazione Cariplo; ref. n.: 2017-1241; Period: 01/08/2018-31/07/2021. Online information material: http://www. cmsondrio.it/website/images/brochure_web1.pdf. In the text, it will be abbreviated as the RADICI Project.

${ }^{2}$ Title of the research action: Il centro storico di Chiuro: un laboratorio di architettura (The urban settlement of Chiuro: an architecture laboratory), part of the topic n. VII: "Antichi centri storici"-“Ancient historic centres". Implementing body: Municipality of Chiuro (Sondrio); project partner: Scuola Superiore di Studi sulla Città e il Territorio-SSCT (Advanced School of Studies on the city and region. website: www.cittaeterritorio. unibo.it), Alma Mater Studiorum-University of Bologna (Scientific coordinator: Professor Luca Cipriani)
}

Our main subject matter in the case study is the documentation of the ancient urban centre of the settlement on an architectural scale. Here, some of the medieval characteristic features of architectural complexes, as well as traditional construction techniques, are still preserved under the stratifications of the urban fabric and in many public or private historic buildings and spaces besides some features of the typical landscape in which Chiuro is located, i.e. the terraced vineyards of the surrounding area. Therefore, the project aims to study and document the historic centre based on the integrated use of advanced digital surveying and representation techniques (remote sensing, reverse modelling, 3D modelling), and hightech exploration and viewing tools (virtual reality, augmented reality, game engine) (Cipriani et al. 2018). The application to Chiuro will transmit the peculiarity of the ancient urban fabric (public spaces and private palaces with courtyards and narrow streets), and the morphological features and material used in construction (stone buildings, traditional slate shingle roofs, etc.).

The documentation of the built heritage then becomes the starting point to create an interactive application based on a $3 \mathrm{D}$ textured model able (i) to virtually tell the story of historical events of minor centres and (ii) at the same time to promote cultural and economic aspects and contextually developing new forms of territorial marketing precisely based on Information and Communications Technology (ICT) opportunities; (iii) moreover, the digital documentation and representation system - to be published and shared in public digital repository-becomes instrumental to public administration activities, e.g. as not only as (a) a support platform for the development of tourism and the environment, but also as (b) a tool for the management of the territory for the administration (drafting of detailed urban plans, documentation of chromatic and material information of the buildings), or (c) for the preparation of technical reports and graphic material for specific interventions on existing architecture (virtual simulation of new constructions or alteration to existing heritage) by professionals in the field.

Finally, a particularly significant contribution by the research action on Chiuro will be a shared method for documenting the urban settlements and guidelines for systematic data management, of fundamental importance with a view to creating and testing best practices, afterwards replicable for all similar centres in the Valtellina area. The interdisciplinarity of the research team is, in this sense, essential to achieve all the project goals settled and product a reliable tool for $\mathrm{CH}$ enhancement. Our research team is composed of scholars and professionals operating in the $\mathrm{CH}$ field (architects, restorers, art historians, scholars); in the last year of the project, the team will be supported also by IT specialists to deal in particular with the virtual simulation. 


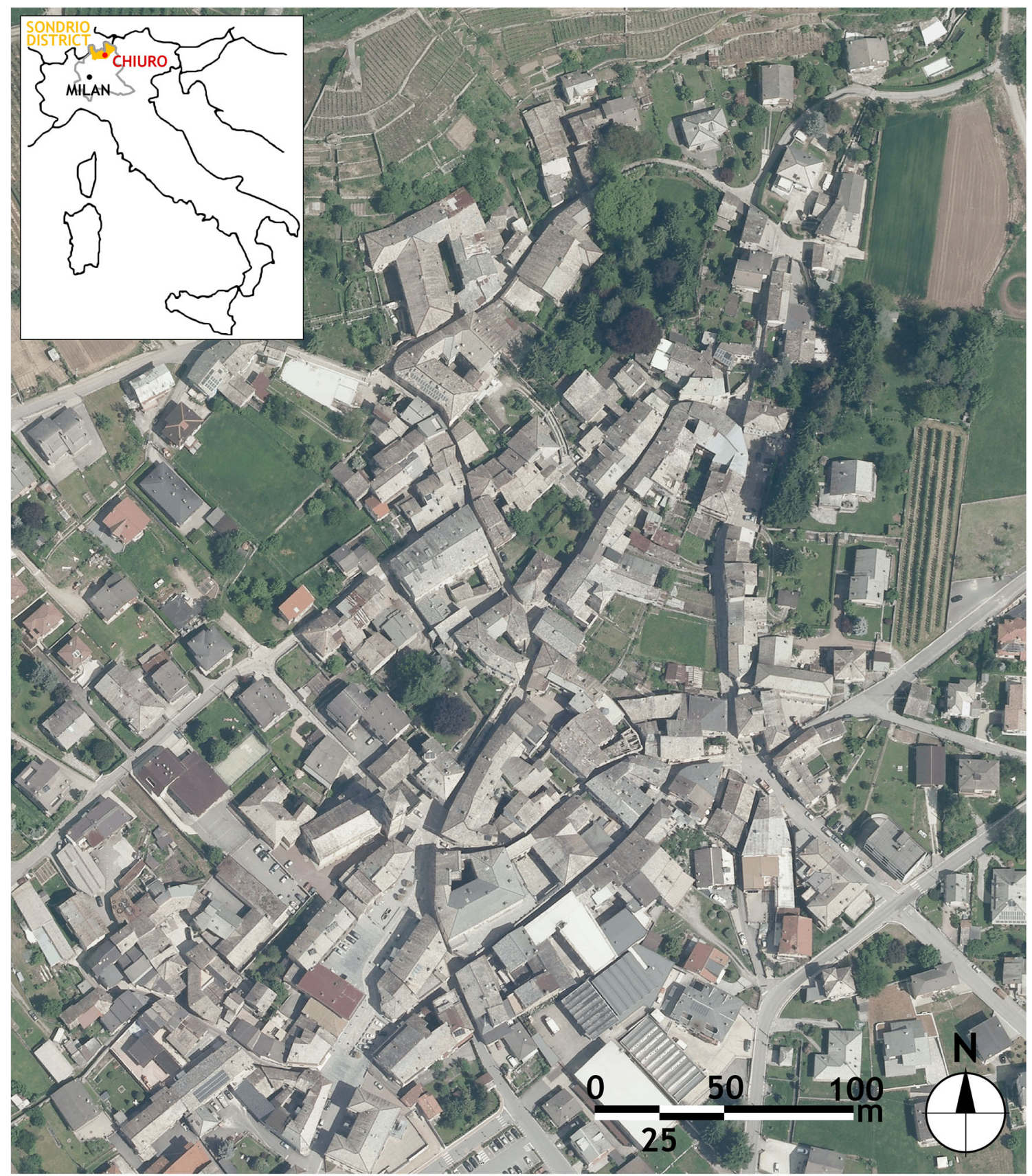

Fig. 1 Digital orthophoto of Chiuro and an overview of its position in Italy; nominal scale 1:2000, year 2012. Credits: Geoportale Provincia di Sondrio, webgis.provinciasondrio.gov.it

\section{The case study: brief historical introduction}

The name of Chiuro appears for the first time in documents of the tenth century, even though its origins date back in prehistoric times. Given its strategic position in the valley as crossroads for trade and commerce, the settlement often played a leading role in the historical panorama of Valtellina. Starting from Middle Ages up to late Renaissance period, important personalities (such as the Quadrio family) were established in the town, contributing to the local economic prosperity and to the thriving building activity, even of a certain artistic interest, as evidenced by the monumental entrance door to the churchyard (1552), the church choir (1527), the mighty Bell Tower started in 1596 (Monteforte and Faccinelli 1989; Comunità Montana Valtellina di Sondrio 2010).

Chiuro's historic centre is hence characterised by a high architectural and environmental quality of public spaces, which is of particular interest with respect to the urban documentation, due to the presence of numerous noble palaces and their historic rural adjacent lots, 
sometimes vegetable gardens and terracing of vine cultivation for wine production, or used for conservation and/ or transformation of local products (oven, mills, etc.).

Several palaces still preserve their original planimetric layout and numerous traces, together with the existing archival documentation, making it possible to read the ancient structure of the medieval village and to find some remains of the ancient medieval towers embedded into current buildings, as is the remains of the castle and tower in Torre Street owned by the military commander Stefano Quadrio (1366?-1438).

In addition, the slate shingle roofs, which are preserved on the majority of the buildings, are a typical feature of local architecture (Fig. 2).

\section{Preliminary experimentations for an explorative model of Chiuro}

As previously stated, the main goal of the documentation of the urban complex of Chiuro is twofold: on the one side to contribute to the knowledge and management of the urban settlement, on the other side to rediscover the hidden medieval elements, still existing in the centre. For the first goal, an extensive use of systematic urban surveying techniques was the basis for the creation of a 3D reality-based digital model; this latter acts as an info-graphic container for complex information, also used for storing historical material recovered under the second objective.
The proposed method aims therefore to collect and systematise data within the 3D model - through meshing, manual segmentation operations/semantic partition, smart polygon count reduction - so that the main features are retained even if the scale of visualisation changes and independently from the tool used to gather data.

The action plan for the research on Chiuro is divided into 3 years (the first one already completed), referring to (1) a first step for the data collection (Fig. 3), (2) the subsequent construction of the SOM from reality-based documentation, and finally (3) the development of a system for a smart use of these models by multiple users in virtual environment.

With regard to the first point, it should be pointed out that the study carried out on Chiuro by the team has already started some years before (since November 2016) in the framework of the project "Chiuro, dal passato il futuro"3 with surveying activities in occasion of educational workshops with students from different degree programmes of the Alma Mater Studiorum-University of Bologna. During these years, three data acquisition campaigns were carried out (both photographic and terrestrial laser scanner-TLS) of the urban nucleus of the city, where ancient elements - bearing witness to the medieval settlement of the urban complex-were more likely to be found (Cipriani and Fantini 2018).

Following this preliminary data collection, one additional acquisition campaign has been carried out within the RADICI Project (see the "Data acquisition" section), in order to verify and integrate existing collected data and to complete the 4

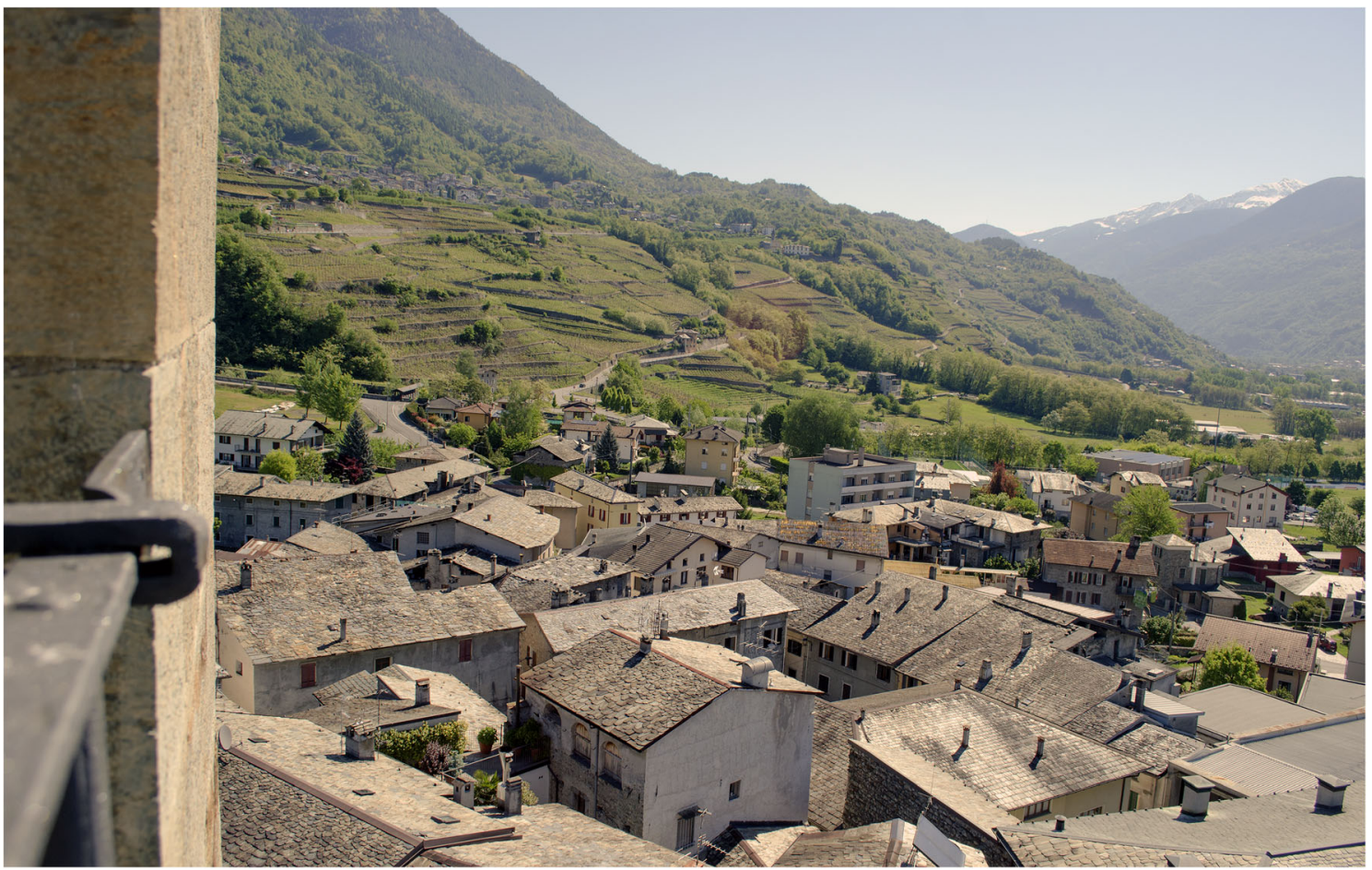

Fig. 2 View of the old town centre and its slate roofs from the top of the Bell Tower 


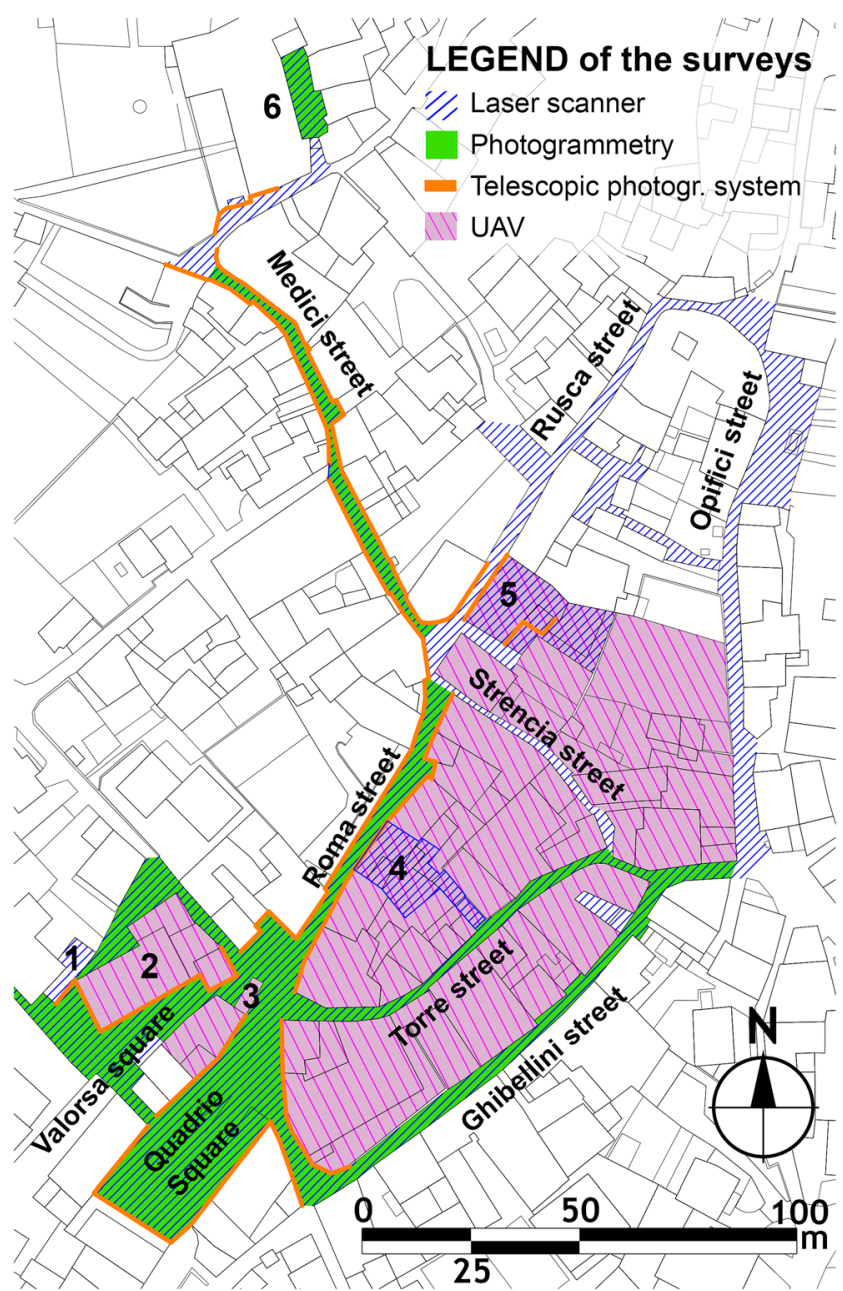

Fig. 3 Data collection at the end of 2019. Key of the main buildings: 1 Disciplini portico, 2 Church of Saints Giacomo and Andrea, 3 Gate, 4 Andres Palace, 5 Gatti Palace, 6 Loggia of the Quadrio de Maria Pontaschelli Palace

main topics of the surveying activities, whether urban or landscape, related to the general project:

1. Urban fronts and public/private spaces (streets, squares, paths, courtyards, ...);

2. Architecturally and historically significant buildings: military buildings (tower, gate in Fig. 4a, castle, city walls, ...); religious buildings (church, chapel, ...) (Fig. 4b); productive buildings (loggia, wine cellar, ...) (Fig. 4c); residential buildings (palace, villa, ...);

3. Rural courtyards and private open spaces;

4. Water system (creek, river, ...) and related spaces and buildings (water mill ...).

Therefore, the integration has made it possible to complete the survey of the central area of the historic centre, acquiring nearly 400 scans, to obtain a better coverage of the information related to the urban nucleus.
The second step of the action, still ongoing, provides the structuring of the collected data in the 3D modelling of the urban centre, organised on a first level according to significant sections, that is streets and blocks (only the main fronts of buildings), and on a second level creating a more detailed digital model (SOM) only for significant elements (important buildings, architectural details, decorations, ...), semantically divided through segmentation operations (see the "Modelling workflow" section).

This modelling solution can be defined as "hybrid", since the digital simulacrum consists of reality-based models inserted on low detail meshes, in turn obtained with traditional geometric modelling systems based on 2D geographic information documentation (Sistema Territoriale InformativoTerritorial Information System). In fact, due to the duration and complexity of the project (many operators and devices, different campaigns, partial lack of information until the end of the project, etc.), our strategic approach to complete the explorative model provides for a first phase of general and highly simplified geometric modelling of the whole centre based on available cartography (north-oriented, scale $1: 2000)$ and neighbouring landscape (contour lines of the slopes of the mountains) (Fig. 5).

This model performs a dual function, on the one hand becoming a masterplan for the coordination of surveying operations (documentation progress, activity priority, etc.), and on the other hand it represents a low detail background to be used in the real-time interactively explorable application. Then, once completed one by one the mesh models of all the buildings (SOM), these latter will be substituted - by replacement or integration - into the general model (see the "Modelling workflow" section).

Thus, the different level of detail is directly proportional according to a prior established parameter of importance, depending on the historical or cultural interest of the building and reserving the necessary accuracy for each type of element: a modern building with no artistic value, hence with a lower request of accuracy, will be considerably simplified, while a historic building or decorations would be more detailed. This approach meets the requirement of (i) managing in an efficient and coherent way a huge amount of data (the whole centre) diversifying the accuracy of each building and (ii) allowing a multi-stage process for the completion of the final model.

Finally, for the third point, to be developed during the next year (see the "Outputs" section), the obtained models, complete with colour and normal maps, would then be introduced into a virtual application. In fact, the use of reality-based models through real-time applications and purpose-designed games on common devices allows general users a better knowledge and understanding of complex object difficult to appreciate or impossible to visit (Apollonio et al. 2018a). Moreover, the use of game engines provides an effective 


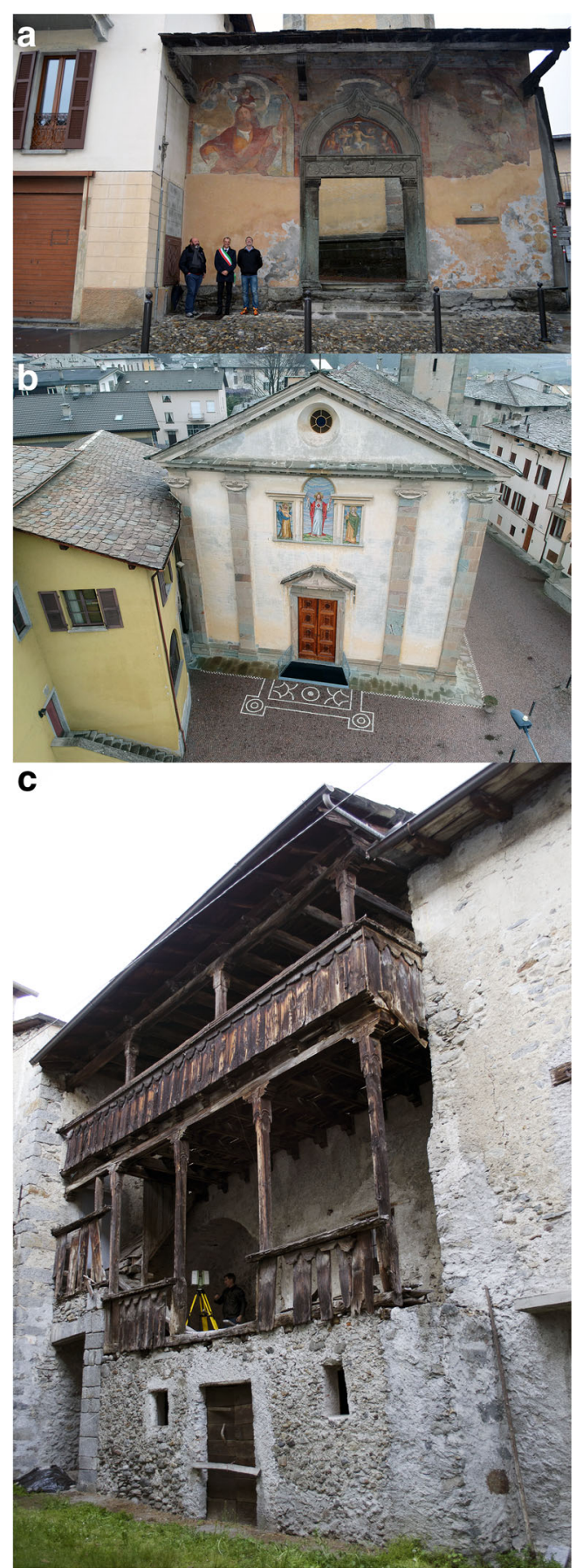

Fig. 4 Most significant buildings of the centre: a) the sixteenth-century gate in the main square, b) parish church of Saints Giacomo and Andrea, c) wooden loggia of the Quadrio de Maria Pontaschelli Palace

system for dissemination of cultural heritage, being an optimal tool for web visualisation and immersive experiences (GarcíaLeón et al. 2018).

\section{Data acquisition}

The digital acquisition of Chiuro mainly covers urban streets and facades, only in some cases including the interiors of historic buildings and courtyards adjacent to the public street, with an approach to documentation that starts from the single street and the facades overlooking them, and privileges the completion of urban blocks, in some cases crossed by internal semi-private paths or private open spaces (Fig. 6).

Concerning data gathering, standard practices of surveying and representation of $\mathrm{CH}$ through digital techniques were adopted in order to document and construct complete 3D models. On this basis, both a terrestrial laser scanner and close-range photogrammetric survey have been carried out. Missing data, such as upper parts of elevations, have been integrated by a campaign with a photogrammetric telescopic shooting system (3D EYE - carbon fibre telescopic pole up to $9 \mathrm{~m}$ maximum height, with stabilised and remotely adjustable camera controlled by a tablet). Moreover, a UAV survey of two emblematic buildings has been carried out to document the missing roofs.

Laser scanning campaigns have been carried out with a total number of 387 scans acquired (Table 1).

Close-range photogrammetric campaigns count more than 5000 photos for the surveyed area, shot with different reflex cameras in RAW/NEF format (Table 2).

Nevertheless, with reference to the survey documentation, some important issues still remain to be completely solved:

- Integration of non-homogeneous data: the integration gives rise to some problems due to coordinate systems conversion between scanner devices;

- Completeness of the buildings: generally architecture is lacking most roofs due to the point of scanning (at eye level) and integrated with UAV survey only for major buildings; geometry is partially incomplete due to (a) fixed and moving obstacles, (b) maximum device range, so that rear facades behind fences are not documented; thin elements not properly acquired/reconstructed in both methods (Fig. 7);

- Replacement of the geometric model with high-detail reality-based mesh models from laser scanner: the substitution raises the question of how to deal with the different level of accuracy of the cartography and the scanner data, closer to real dimensions, hence having gaps and inconsistencies between the two models;

- Texturing of the front elevations: in spite of the pictures captured with 3D EYE, there still exist holes in the textured surface, due to the impossibility to cover the entire area because of the time-consuming activity of taking a large number of photos with the device, and once again for the presence of obstacles and obstructions;

- Logistics problems: mainly logistical issues arise from accessing private properties and taking measurements in the narrow public streets, frequently due to the traffic that 


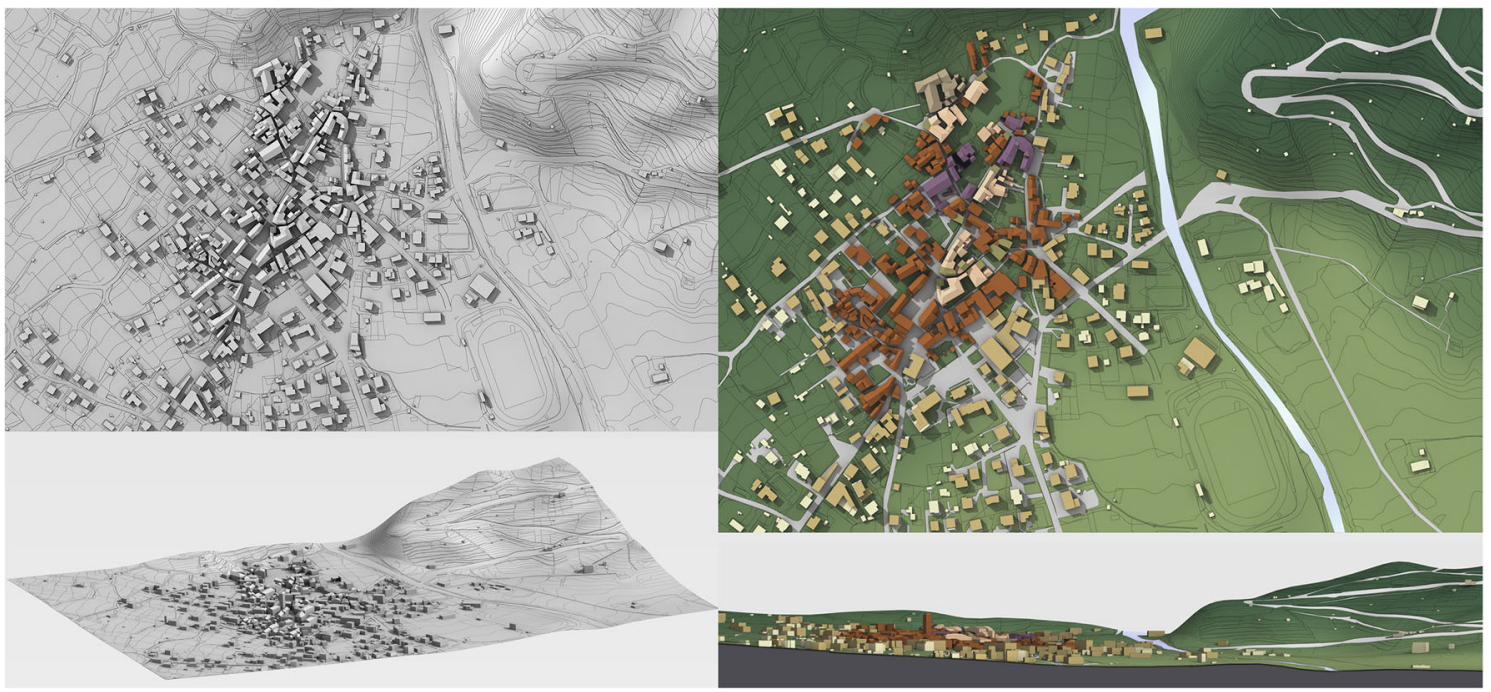

Fig. 5 Geometric simplified model of Chiuro with main architectural features and development phases of the settlement. Credits: M. D'Amico, F. Fantini, year 2017

then interrupt operations; moreover, bad weather conditions affecting the possibility of surveying must be taken into account;

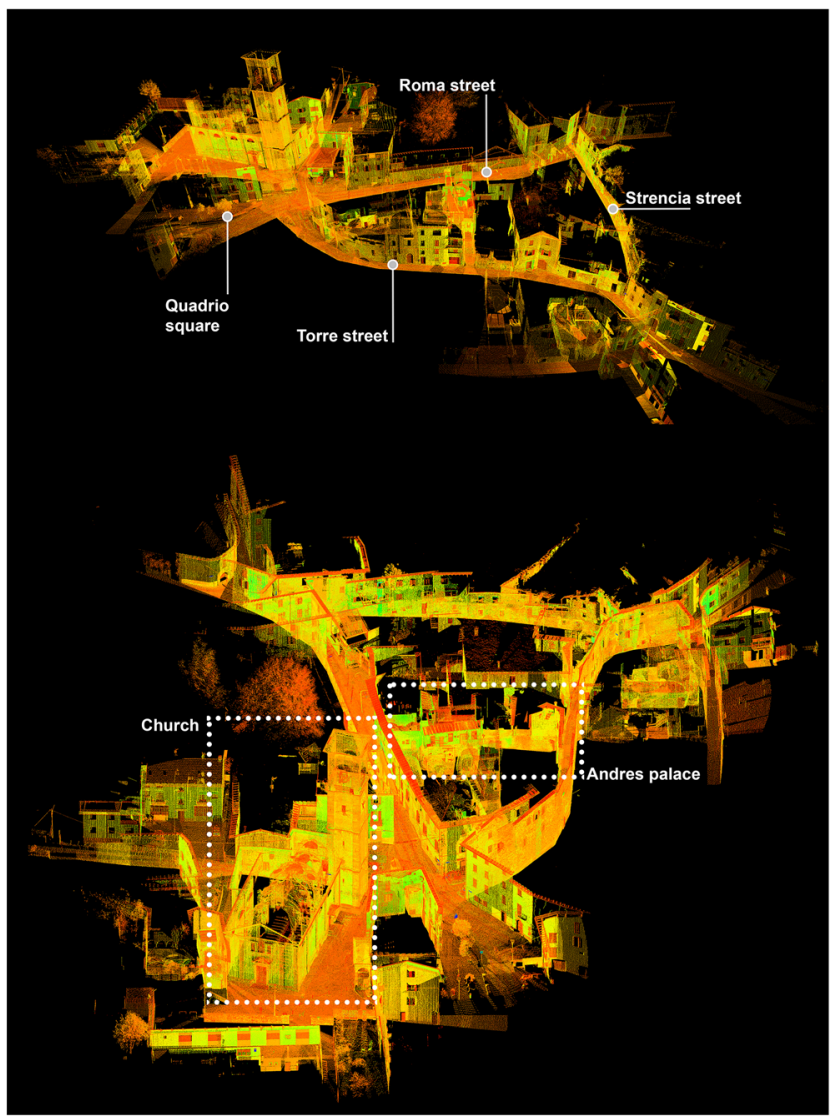

Fig. 6 Global point cloud of the central area (Roma, Torre and Strencia Streets; Valorsa and Quadrio squares, total scans: 93; total points: about 637 million; extent of the area: about $6590 \mathrm{~m}^{2}$ )
- Processing tools: most of the used software for processing data are proprietary software, because often open source applications do not support the large amount of data; however, some experiments will be carried out using only open source software for processing.

\section{Modelling workflow}

The modelling workflow developed is split into two steps: (1) a first draft model, a sort of template for activity planning, obtained with direct geometric modelling tools, and (2) reality-based highly detailed models, progressively acquired campaign after campaign.

The first simplified, but complete, model of the whole of Chiuro has the purpose to show in a graphic form the whole extent of the settlement and the main historical phases. Its purpose is to be a sort of masterplan aimed at scheduling automatic and manual modelling of Chiuro obtained by sensors during the three years project development. The approach adopted here is quite far from standard multi-scale representations of semantic 3D city models (Gröger et al. 2012) since our goal is the achievement of a photorealistic model of the town, with a differentiated level of detail established on the base of a storyboard. This model was created through a conventional solid or NURBS modelling workflows based on commercial applications such as Autodesk AutoCAD software version 2018 (extrude, slice, offset tools, etc.) and McNeel Rhinoceros (release 6) for generating terrain starting from contour lines and vector information based on available official cartography (GIS). 


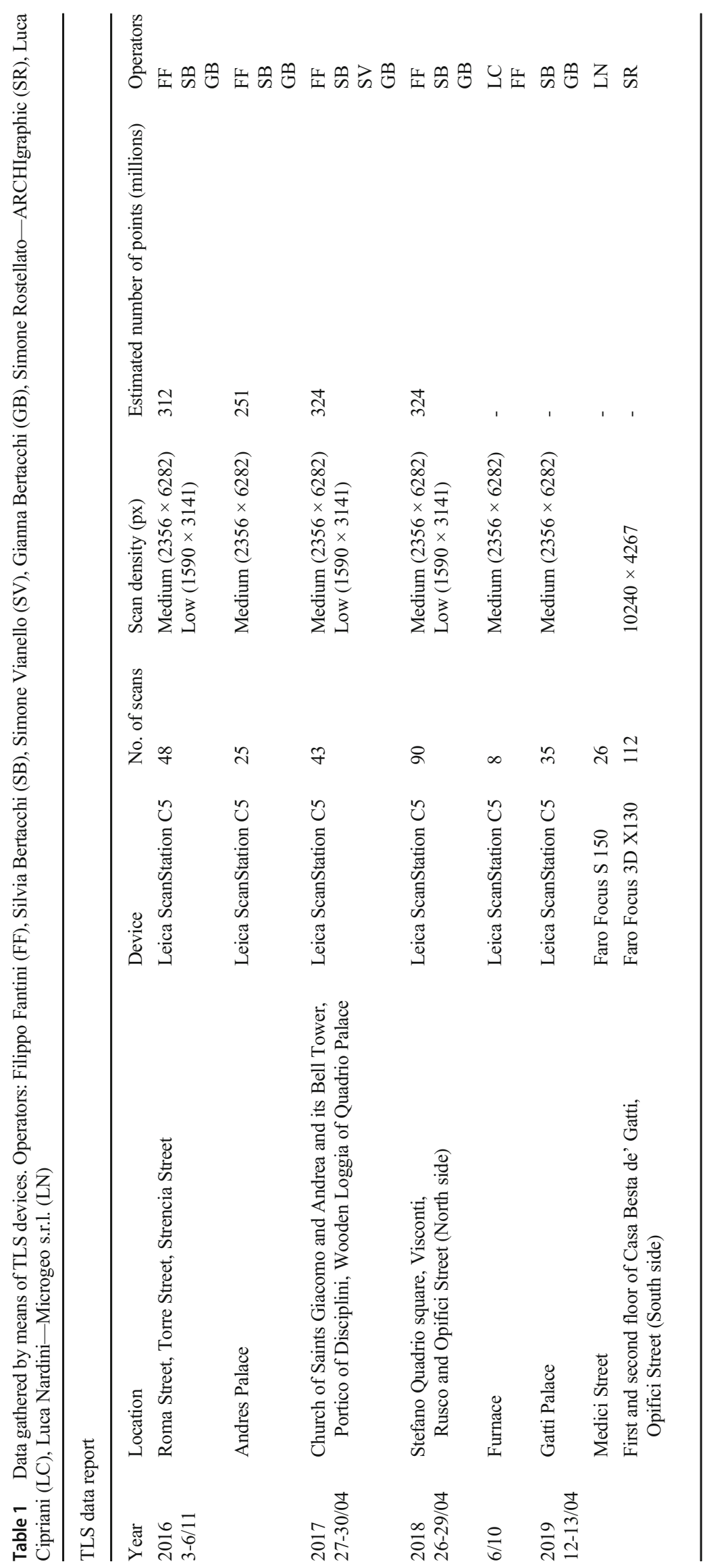




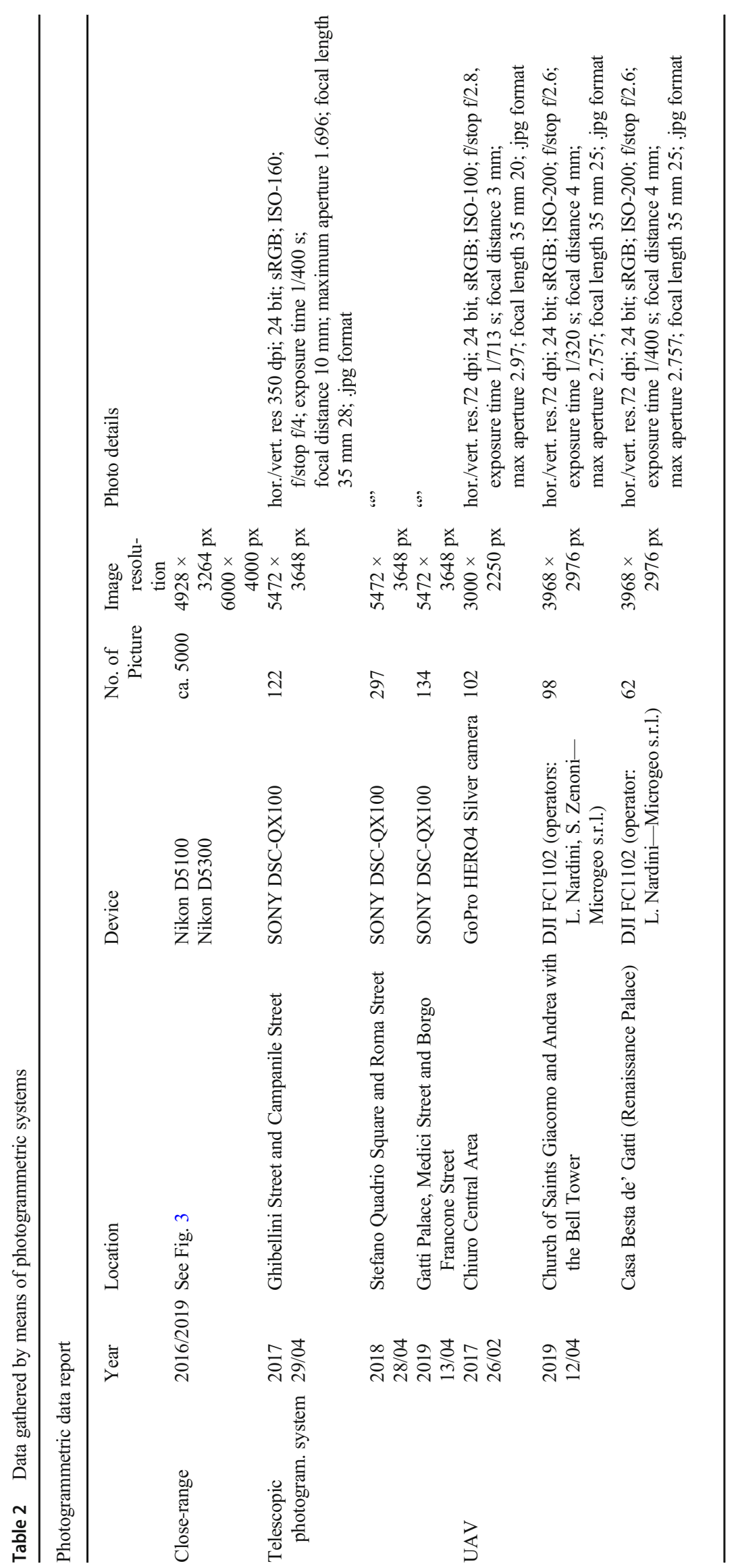




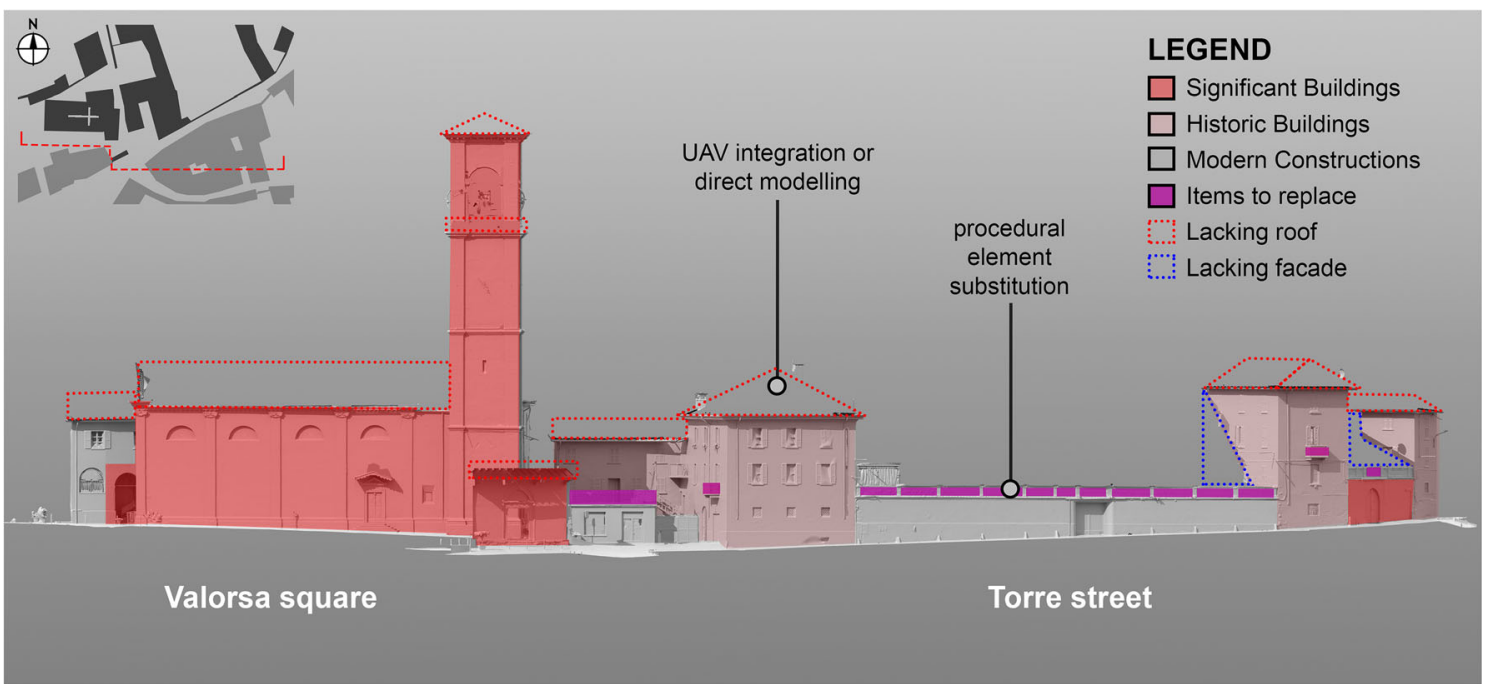

Fig. 7 Orthographic view of the mesh of the church, the portal and Roma Street's urban fronts. Coloured transparent shades indicate the relevance of the buildings; dotted lines lacking architectural parts not acquired by means of TLS

Regarding the modelling workflow from reality-based data, our consolidated pipeline to achieve reliable, multi-purpose models is described in Gaiani et al. (2017) and Cipriani and Fantini (2018); to this, some changes have been made to improve the workflow according to the focus of the research and to customise the process for the case study.

The software used for the general management and the alignment process of point clouds is Leica Geosystems Cyclone, version 9.2. Alignment between scans has been performed through common points, both reference targets and other evident architectural features, following a standard procedure (manual detection and labelling of targets, registration adding scans one by one, and the final phase based on a ICP solution (final registration based on cloud-constraint, and checking of RMS results, mean absolute error).

In order to improve the results of the photogrammetric reconstruction process, pictures are subjected to a pre-processing step to balance images (colour correction) and converted into .TIF format for processing in Agisoft Metashape version 1.5 (formerly PhotoScan, version 1.4). The software allows (i) to create highquality models of architectural elements not surveyed by means of scanner laser or needing more detail (4step process from 2D pictures to 3D textured mesh: alignment, generation of dense cloud, meshing and texturing) or (ii) to produce textures for range-based models (3-step process: alignment, dense cloud, texturing of the imported 3D model).

Our data processing methodology is a six-step methodology (Fig. 8) and can be summarised as follows:

1. Modelling task management: the final goal of the procedure is a SOM; their visible shape in a game engine is due to the contribution of different sensors. Active sensors supply (1) the horizontal connective (public/private spaces), and (2) the elevation fronts (urban facades) in the form of a point clouds. Passive sensors supply (3) building's roofing in the form of a mesh. SOM will combine all the three categories, each one corresponding to a specific processing protocol aimed at preserving the higher visual reliability and geometric detail in a compressed way. The amount of direct modelling for each element belonging to the SOM must be carefully planned in order to organise the work and avoid waste of time. The modelling solutions adopted for missing or poorly documented elements by active and passive sensors, e.g. tiny metallic grids, decorated railings and protection gratings, are subdivision surfaces combined by means of a node-based procedural interface, enabling on-the-fly creation of several different versions of the same category of 3D assets (Fig. 9b). The choice of subdivision surfaces (SDS), rather than other modelling techniques like NURBS, is aimed at achieving "light" variable level of detail representations of both smooth and complex shapes (Adembri et al. 2018; Cipriani and Fantini 2018). Low frequency details such as those characterising streets, squares and paving can be easily achieved by means of quad remeshing solutions, while flat vertical masonry can be drastically reduced in the number of polygons by means of fast manual retopology tools. Table 3 summarises the main characteristics that the models belonging to the three categories should have:

2. Segmentation: once split the comprehensive dataset in smaller modelling "problems", high-definition mesh models from terrestrial laser scanner 


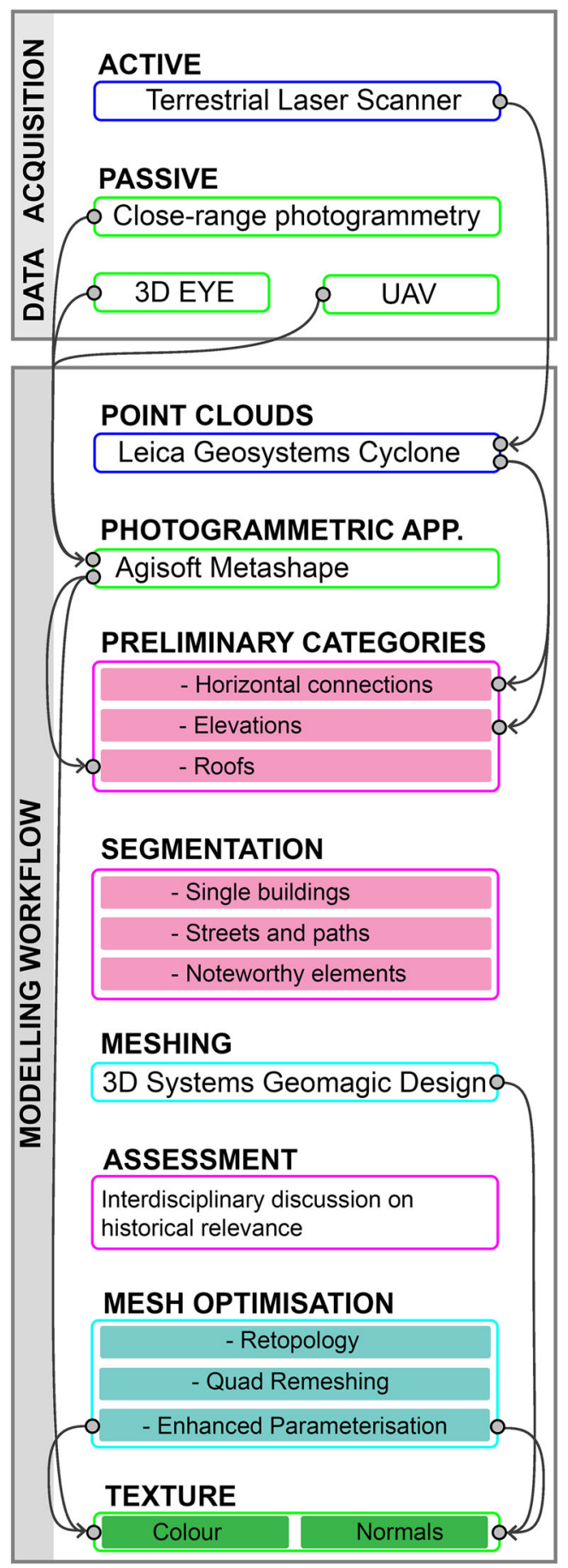

Fig. 8 Proposed workflow

campaign data are created. In order to do that, a first manual point cloud segmentation is carried out for the purpose of exporting towards meshprocessing applications (i) single buildings, as well as (ii) streets and paths, besides (iii) further noteworthy elements. ${ }^{4}$ In case of complex urban scenarios, the use of semantics is aimed at splitting a complex task into smaller, more easily achievable ones, since the meshing of a whole town at once is not a viable solution in terms of hardware and software capabilities. Smaller models can be more easily processed, in order to supply game engines with optimised 3D assets, characterised by an optimal parameterisation and, consequently, an optimised texel density (García-León et al. 2018). In practical terms, it is important to export from the point cloud application single.PTX files-based on semantics - that are slightly bigger than the building/urban element they must represent; model boundaries will be removed in following phases of the process;

3. Meshing: thanks to 3D Systems Geomagic Design X application, every segmented point cloud is converted into meshes of triangular polygons to be transformed into master models (Fig. 10). In this phase, the production of a 2manifold model is not a measure issue: the point is to get rid of main topologic and geometric defects. Resulting meshes, roughly divided in compliance to semantics will then be optimised and integrated ${ }^{5}$ through techniques borrowed from entertainment applications. The following sub-categories of the master model concerns historic, cultural and social values. The ontologies have been studied in collaboration with the interdisciplinary team, basing upon precedent studies and standards (Bertacchi et al. 2018). Some of these categories are: Streets (S), rural Courtyards (C), and elements of the Water system (W); among the latter, modern constructions (MC) and historic buildings (HB) - ranging from the medieval to the late Renaissance period - in turn divided into residential, military, religious and productive buildings (palace- $\mathrm{P}$; tower $-\mathrm{T}$, gate $-\mathrm{G}$; church $-\mathrm{CH}$; loggia $-\mathrm{L}$; oven $-\mathrm{O}$; mill-M; wine cellar - CE, etc.). In practical terms, a major topic of this step is that various point clouds contribute to the building description, and it is required to delete unnecessary contributions and partially unneeded elements or obstacles (parts of the building that are not relevant, passers-by and cars, etc.). This procedure, even if time-consuming, allows better results and less editing in the following steps. High-resolution meshes coming from active and passive sensors can be merged, or not,

\footnotetext{
${ }^{4}$ In the near future, the research on automatic segmentation will supply users with software solutions for semantic enrichment of models based on machine learning solutions: after a manual training phase, algorithms will provide automatically an initial classification. Machine learning is a scientific discipline concerned with the design and development of Artificial Intelligence algorithms that allow computers to take decisions based on empirical and training data. For a survey on current segmentation methods, see Grilli and Remondino (2019).

${ }^{5}$ The integration process concerns the merging, inside a single asset, of meshes coming from different sensors and ranging techniques, including 3D EYE and UAV.
} 
Fig. 9 Modelling solution for details: a) optimised model of a building in Quadrio Square; b) original and optimised model of Roma Street with the detail of the railing, created with a procedural workflow
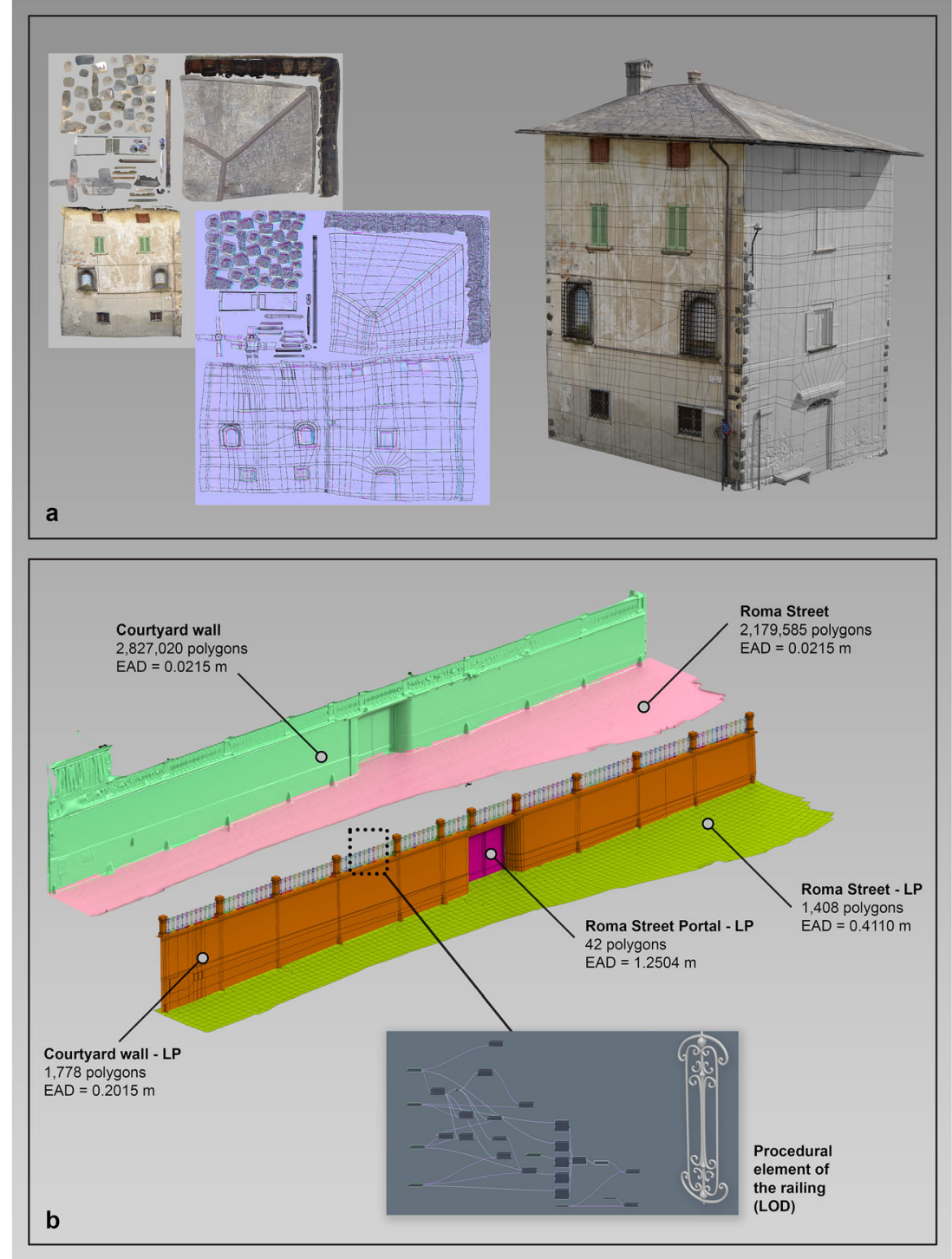

depending on specific situations. Single master models will then be exported in .OBJ format;

4. Assessment: as a result of a phase of interdisciplinary discussion with experts of art history, architects, and restorers, the master model is taken into consideration in order to understand the historical relevance of each building and consequently choose different levels of accuracy required for models, with higher detail depending on the major historical importance;

5. Mesh optimisation: the use of various mesh optimisation techniques has the aim of obtaining low-resolution versions starting from highly detailed meshes, then improving the model's usability inside game engine applications (Fig. 11). Basically, the research group adopted two techniques: (a) one manual (retopology), (b) the other automatic (quad-dominant remeshing). Manual retopology (a) was used for simplifying modern constructions (historically not significant buildings and of less interest for the project) characterised by simple geometric shapes. On the contrary, automatic quad-dominant remeshing (b) was applied to significant historic buildings, afterwards carrying out a second segmentation to split the model into elements characterised by more complex morphologies (presence of carved/sculpted elements) or as an alternative by more simple surfaces. The advantage of using quads, namely polygons of four sides, is due to their higher consistency with geometric features of buildings unlike triangles that cannot follow the natural flow of a surface. In addition, low-poly models facilitate two operations: parametrisation and completion;

6. Texturing: normal maps and apparent colour. In order to apparently re-establish the original detail of the modelled 
Table 3 Modelling tasks overview: criticalities and strategies. The maximum allowable deviation depends both on the semantic subdivision and the modelling solution used

\begin{tabular}{|c|c|c|c|c|c|}
\hline \multirow[b]{2}{*}{ Horizontal connective } & \multirow{2}{*}{$\begin{array}{l}\text { Sensor } \\
\text { TLS }\end{array}$} & \multicolumn{2}{|c|}{ Processing criticalities } & \multirow[t]{2}{*}{ Modelling solution } & \multirow[t]{2}{*}{ Maximum allowable deviation $(\mathrm{cm})$} \\
\hline & & Low $\rightarrow$ & Low frequency details & & \\
\hline & & & - Low relief paving & Quad dominant remeshing & $\leq 4 \mathrm{~cm}$ \\
\hline \multirow[t]{13}{*}{ Elevation fronts } & TLS & High $\rightarrow$ & High frequency details & & \\
\hline & & & - Carvings & Manual retopology & $\leq 1 \mathrm{~cm}$ \\
\hline & & & - Mouldings & Manual retopology & $\leq 1 \mathrm{~cm}$ \\
\hline & & & - Bossage & Quad dominant remeshing & $\leq 2 \mathrm{~cm}$ \\
\hline & & & - Tiny elements & Procedural & $\leq 5 \mathrm{~cm}$ \\
\hline & & & - Window grilles & Procedural & $\leq 5 \mathrm{~cm}$ \\
\hline & & & - Traffic signs & Manual retopology & $\leq 1 \mathrm{~cm}$ \\
\hline & & & - Public lighting devices & Manual retopology & $\leq 1 \mathrm{~cm}$ \\
\hline & & & - Downspouts & Procedural & $\leq 5 \mathrm{~cm}$ \\
\hline & & & - Intrados beams & Quad dominant remeshing & $\leq 2 \mathrm{~cm}$ \\
\hline & & Low $\rightarrow$ & Low frequency details & & \\
\hline & & & - Flat vertical masonry & Manual retopology & $\leq 1 \mathrm{~cm}$ \\
\hline & & & $\begin{array}{l}\text { - Additional elements } \\
\text { (benches, swings, etc.) }\end{array}$ & Manual retopology & $\leq 1 \mathrm{~cm}$ \\
\hline \multirow[t]{3}{*}{ Roofing } & UAV & Low $\rightarrow$ & Tiny elements & & \\
\hline & & & - Chimneys & Manual retopology & $\leq 1 \mathrm{~cm}$ \\
\hline & & & - Antennas & Procedural & $\leq 5 \mathrm{~cm}$ \\
\hline
\end{tabular}

surface, normal maps have been calculated using the typical render-to-texture solutions called baking (Cohen et al. 1998; Guidi and Angheleddu 2016). Texture application can run through SfM applications, since laser scanner and photogrammetric campaigns were carried out simultaneously based on a common network of RAD coded targets. In summary, digital images are captured in RAW format, then balanced with Adobe Photoshop and converted into .TIF format (lossless format), finally processed with Agisoft Metashape version 1.5 to achieve the final texture. Consistency of coordinate systems is assured by entering the coordinates of target reference points. Image processing workflow details are fully explained in Gaiani et al. (2017).

\section{Outputs}

As regards the possible virtual outputs, based on the current trend for the enhancement of the territory through virtual access and dissemination of contents, the research activity is interested in developing an application both for tourism and citizens to promote the discovery of the area. Indeed, there is no doubt that in recent years, tourism and territorial marketing have benefited when cinematographic sets or even video games choose a particular location, which could be referred to as the "Assassin's Creed effect", an emblematic example demonstrating the rising phenomenon to promote through video game works a place as well as to popularise cultural, social and identity topics; moreover, to generate tourist numbers for visiting real places discovered through digital media (the socalled film or video game tourism), valuable opportunity for a local revenue.

Starting from this large amount of 3D models, the challenge to convert available information into a satisfying interactive experience using game engine software is not a simple task due to the great number of polygons characterising reality-based models. The resolution of each master model, namely its edge average distance (EAD), is not suitable with one of the main challenges of this Project that is the keeping of reliable and detailed 3D assets while keeping as high as possible frame rate (García-León et al. 2018). In this sense, steps 5 and 6 supply a robust solution aimed at recovering the resolution of highly detailed meshes and, consequently preserving artistic qualities and material information while experiencing a fluid and realistic visualisation. Optimisation of reality-based models is carried out through a testing phase in order to define performance and limits of the game engine with particular reference to two main factors: maximum polygon threshold and texture resolution.

The final interactive application will meet users' needs to explore the complete model, interact with it, meanwhile 


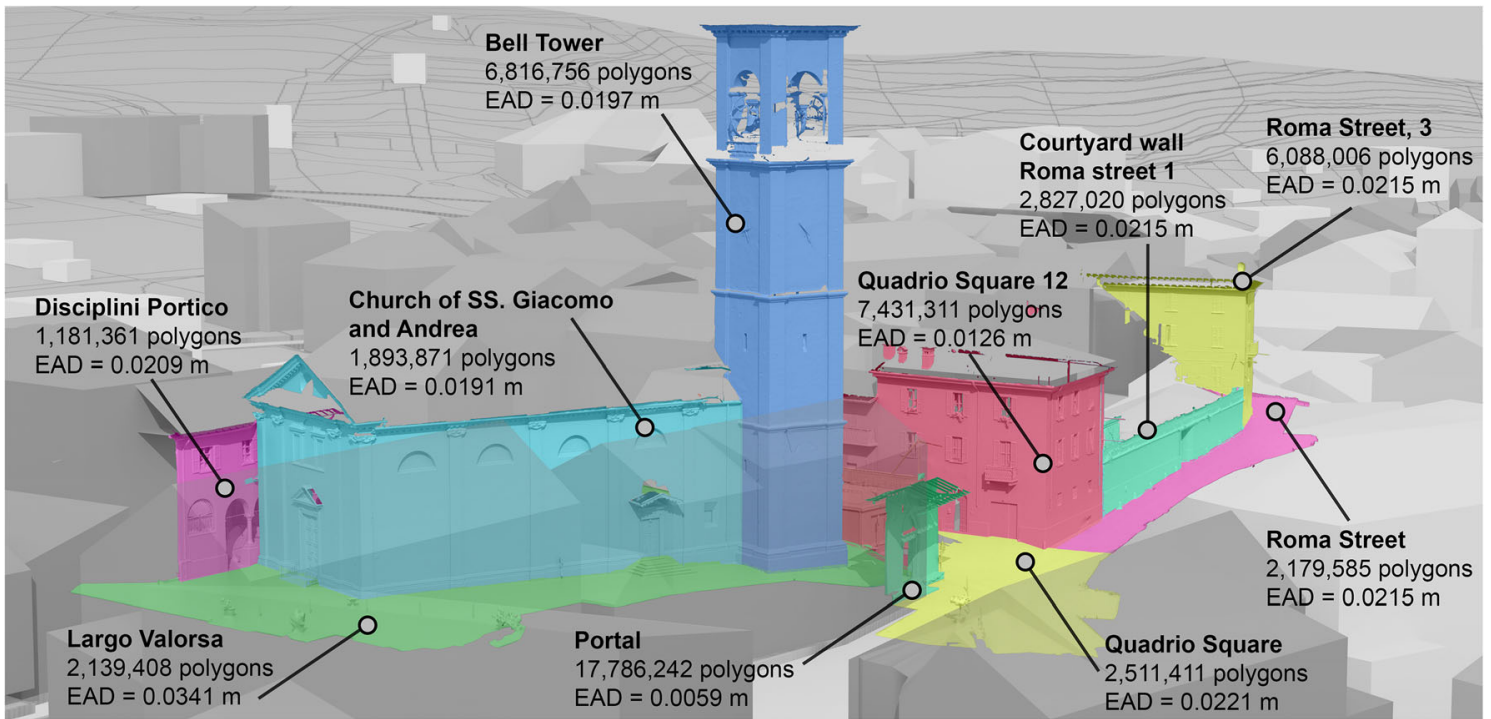

Fig. 10 High-poly meshes of some buildings from TLS data with number of polygons and edge average distance (EAD)

appending notions about Chiuro's historic centre. Starting from the third year of the Project, simplified models of architecture will be introduced as placeholders in the game engine (Epic Games Unreal Engine 4) as context elements essential to understand architecture and space. Subsequently, with the progress of sensors data processing, simplified models will be progressively replaced by optimised assets representing $\mathrm{CH}$.

The proposed workflow has been applied to the sixteenth-century gate situated in the main square of the town (Fig. 12). The mid-poly model, obtained by the master model mesh, has been optimised with a quad-remeshing procedure: starting from the triangular mesh, this automatic retopology procedure creates a surface composed by quads (Fig. 13-1a-c) that makes the semantic partition easier to achieve. Texturing on the high-resolution mesh has been performed by means of Agisoft Metashape Professional; normal maps of each model have been created by baking the high-poly mesh in Foundry Modo 12.0v1. Then, the 3D model with colour textures and normal maps was imported in the game engine Unreal Engine to build a test scene. Normal maps and textures as well as the UV mapping

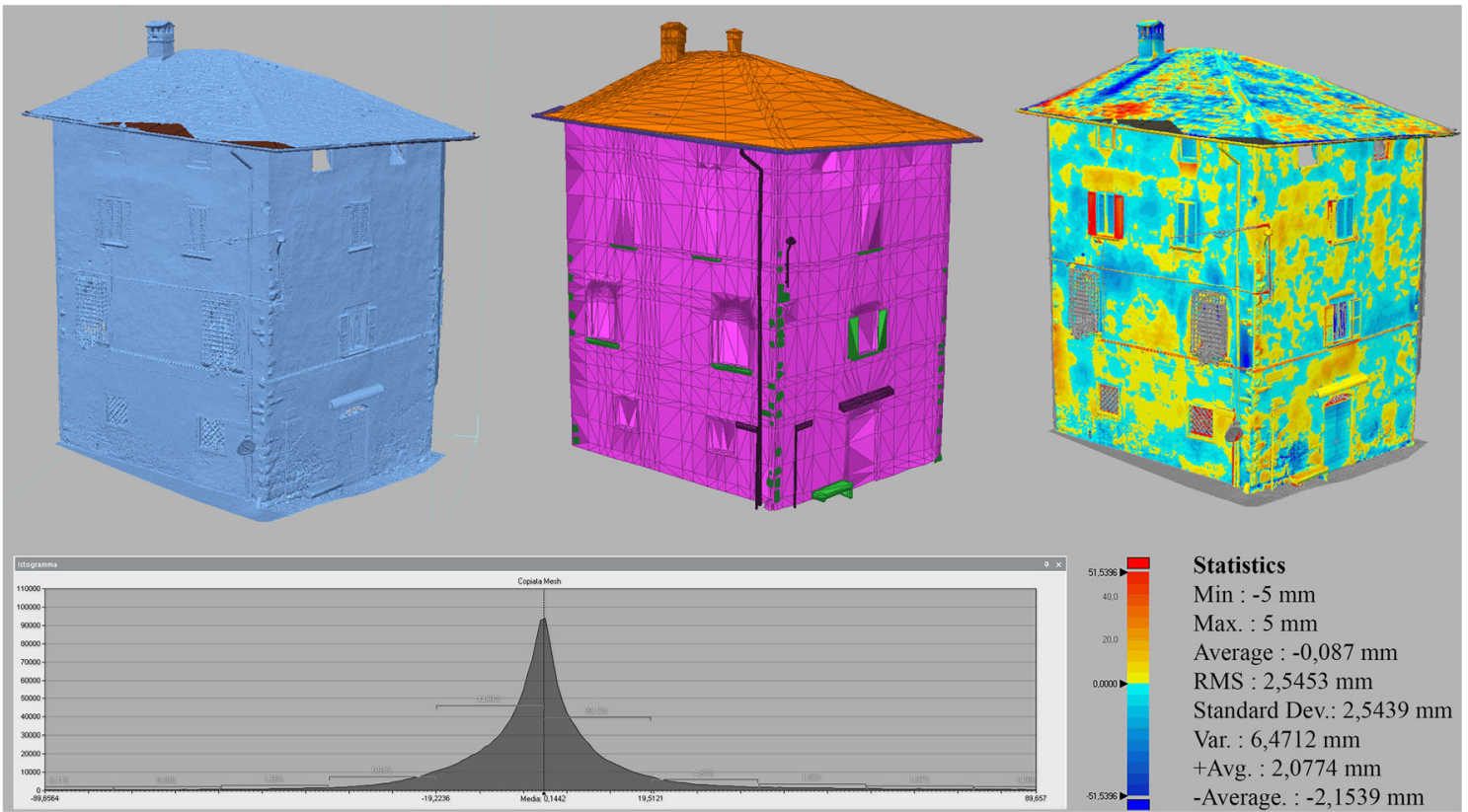

Fig. 11 High-detailed model and retopology mesh. The third image shows the deviation and it is an example of the acceptable simplification range, as indicated in Table 3, right column 
reference system are automatically recognised in the software. The scene has been created using a low-poly model of the streets and the buildings, and a medium-poly of some areas of interest, i.e. the gate of the main square. The scene illumination has been set up using a sky sphere, a sky light, a directional light and some spotlights. Real-time renders have been tested on a medium-quality laptop with the following specifications: Intel ${ }^{\circledR}$ Core $^{\mathrm{TM}}$ i7-5500U with Intel HD Graphics 5500 (2.4 GHz, 4 MB cache, 2 cores); 16 GB SDRAM DDR3L $1600 \mathrm{MHz}$ ( 2 x 8 GB); NVIDIA GeForce 840 M (4 GB DDR3 dedicated). Frames have a 16:9 ratio and a $1920 \times 1080$ pixel resolution (Fig. 13a). Scene simulations have been analysed with Fraps ${ }^{\circledR}$, a software that can show the frames per seconds (FPS) and export statistics (total frames, time, minimum and maximum value, average). The average result on the tested real-time rendering has a value of 74.1 FPS and the minimum value is 55 FPS. These values are compatible to a good smoothness of the video.

The sixteenth century gate has been uploaded on the online platform Sketchfab (https://skfb.ly/6RWCE). Sixteen annotations provide historical information not only on the main decorative elements, such frescoes, but also on the traditional construction techniques (Fig. 13b).

\section{Conclusions and future developments}

The paper defines the progress of the RADICI project and the digital representation of the town of Chiuro. Starting from the documentation of the urban centre, achieved through heterogeneous techniques, the multi-year research is aimed at the following: (i) creating a complete digital explorative model of the central urban area, including a detailed model of the most significant buildings (churches, renaissance palaces, remains of ancient towers, city gates, courtyards, productive buildings, etc.), representing the peculiar features of the urban settlement and its traditional construction techniques, with particular attention to the medieval architectural elements still preserved to this day; (ii) developing an interactive application for virtual storytelling of historical/cultural information to non-experts; (iii) sharing methodical guidelines for the enhancement of minor urban centres based on the integrated use of advanced technologies for the documentation of $\mathrm{CH}$ and pinpointing replicable best practices for other settlements of the region.

To achieve these final objectives, the research Project focusses on the creation of a SOM by integrating different survey data sources and using a stated previous

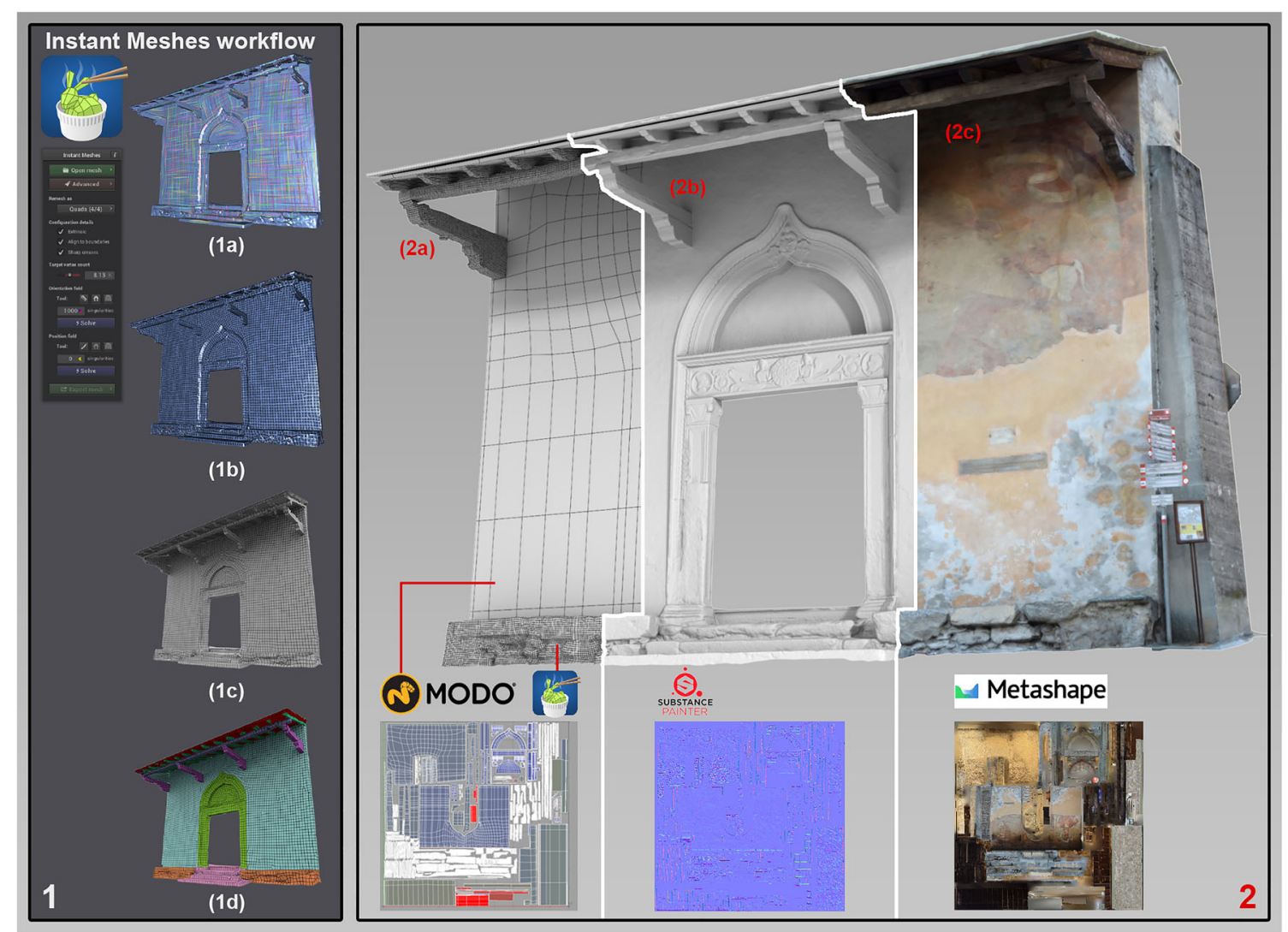

Fig. 12 The sixteenth century gate, Porta Maggiore di San Giacomo, in the main square of Chiuro: 1a-b) Remeshing procedure in Instant Meshes (https://igl.ethz.ch/projects/instant-meshes/); 1c) Quad-dominant isotropic remesh; 1d) Semantic partition. 2a) Automatic or semiautomatic retopology; $2 \mathrm{~b}$ ) detail reestablishment with normal maps; $2 \mathrm{c}$ ) rendering phase 

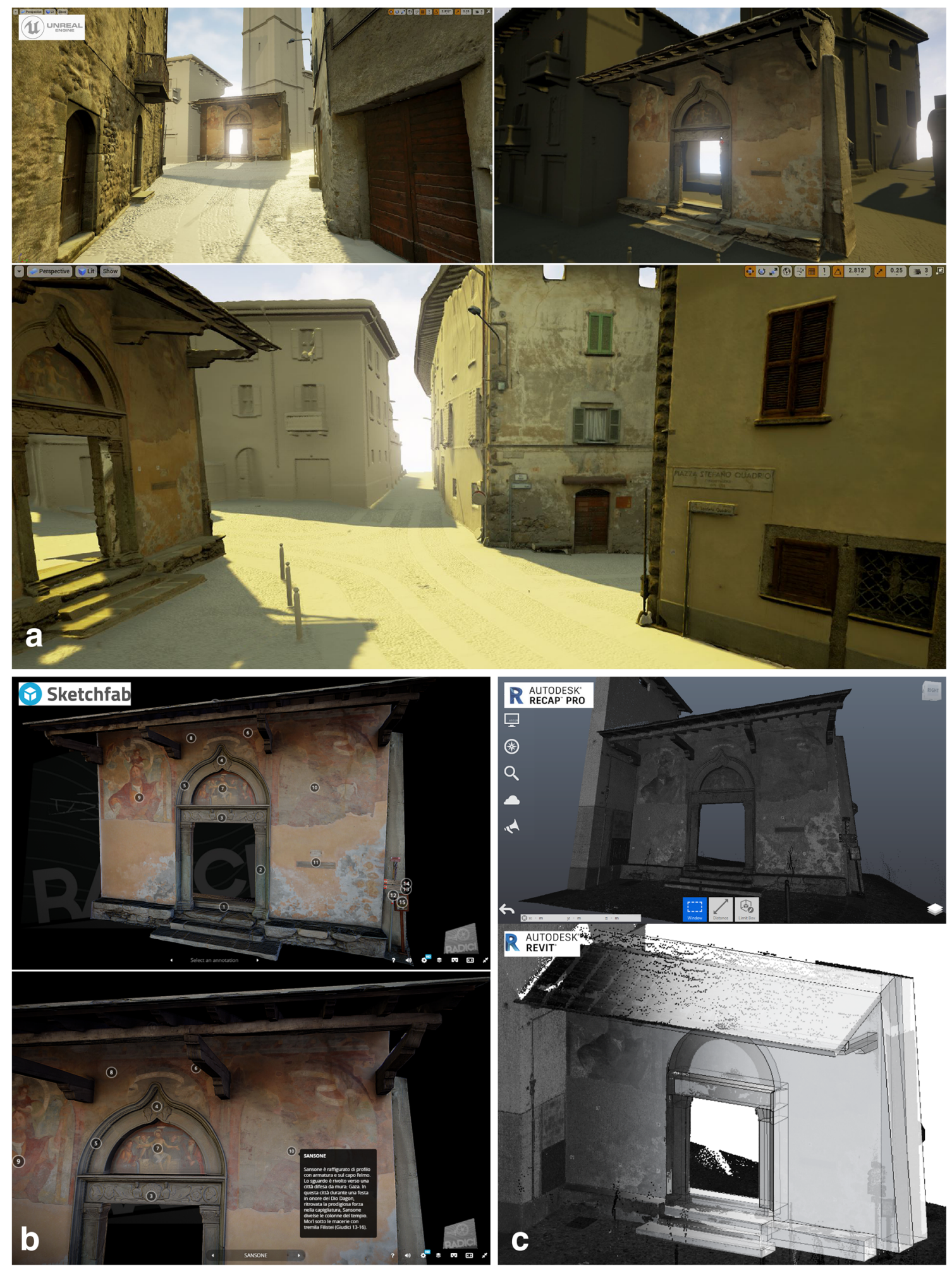

Fig. 13 Some outputs experimented on the sixteenth century gate: a) frames of a walkthrough in the game engine scene; b) the sixteenth gate the decimated point cloud of the gate (about 3 million of points) in Autodesk Recap 2019 (above), an ongoing data processing to transform the gate in a HBIM model in Autodesk Revit 2019 (below)

interpretation of the built environment. The SOM progressively replaces the correspondent elements of a draft template urban model by increasing the level of detail of single buildings on the base of a clear and easily transmissible procedure, whose final aim is to lighten urban visualisation. 
The workflow described tries to address an open issue in the actual research trends, i.e. the use of game engines to visualise and spread digital content of cultural heritage, avoiding the loss of captured detail and fostering visual reliability (Rushmeier 2001). More experimentations will improve the workflow fluidity, finding the most suitable techniques to obtain the SOM. For example, the total substitution of proprietary software with open source applications will improve the replicability. Another improvement could concern the segmentation phase, by including efficient automatic algorithms to avoid or reduce the manual retopology phase, even if the proposed workflow already minimises it.

In addition, the paper examines the methodological aspects regarding the complete exploitation of data from various sensors to obtain a lightweight, portable, easily viewable, and suitable for interaction model. The project on Chiuro also provides the possibility to perform a reflection between three different research fields: (i) the highly photorealistic visualisation of comprehensive urban models; (ii) the integration and compression of sensor output into digital simulacra; (iii) urban digital models with a managerial purpose.

On the one hand, the research of the past years on automation in urban-scale modelling procedures has achieved significant results that facilitate many management practices for public authorities (Gröger et al. 2012). On the other hand, lightweight, high visual quality models require manual, non-automatic and time-consuming procedures performed by highly specialised professionals. A possible strategy that seeks to achieve at least two of the themes addressed, visualisation and sensors' integration, must reach the highest level of realism by limiting the use of manual techniques (typical of pipelines in the 3D artists' domain), facilitating the use of automatic processes, in particular for the realisation of low-poly models.

The chosen path makes an integrated use of quad re-meshing techniques, which allow to optimise some specific parts of the urban settlement (especially some distinctive features of the urban structure), and manual techniques. The latter are concentrated in the simplification of vertical structures, approximated to sequences of quad-planes quickly obtainable with manual techniques. Polygonal modelling tools supply users with simple commands aimed at increasing the level of detail of "box-shaped" buildings and can be considered the only completely manual operation. In general, the procedure leads to models that are not solid (Constructive Solid Geometries), but consists of open mesh sequences, easily to be parameterised and with an adaptive density (higher detail on higher curvature areas). On them, shape with baked normals and colour, complete of apparent colour textures, are superimposed in the parameter space. The key aspect is the adherence of the parameterisation to the semantic partition of low-resolution meshes, while keeping under control the maximum deviation between reality-based model and its lightened version.
Future developments of this ongoing research envisage doing further campaigns for the integration of currently missing urban areas (some of the models still lack the final texture because the acquisition step is still in progress), in order to complete the virtual experience of Chiuro. Another test will concern the transformation of data related to peculiar cultural assets into HBIM models, in order to create a co-working multidisciplinary environment for professionals involved in cultural heritage monitoring and preservation projects (Fig. 13c). Moreover, the interactive and explorable $3 \mathrm{D}$ model, once completed, will be tested to ensure the good visualisation of multi-scale levels of detail. This first experimentation will provide the construction of a historical 3D catalogue of building elements present in Chiuro, reusable in similar settlements, part of the same project.

Acknowledgements The authors would like to thank all partners of the project Le radici di una identità, the project coordinator of the RADICI project Rita Pezzola, the Mayor of the Municipality of Chiuro Tiziano Maffezzini, the Research Team: Paolo Agostini, Giorgio Baruta, Barbara Paruscio; the Survey Team: Filippo Fantini, Simone Rostellato and all students, tutors and professors participating in the educational workshops (years 2016/2019).

Author contribution All authors contributed to the paper writing, digital surveys and data gathering. Luca Cipriani is the coordinator of the research action on Chiuro and supervisor for survey activities, and author of abstract, Section 2 and Conclusions. Silvia Bertacchi is a research fellow for the project on Chiuro's historic centre and author of Section 3. Gianna Bertacchi is a Ph.D. student and collaborator for the surveying activities in Chiuro; author of Section 1. All authors read and approved the final manuscript. All images, 3D models and digital elaborations, if not otherwise specified, are by authors.

Funding Open Access funding provided by Alma Mater Studiorum Università di Bologna.

Open Access This article is licensed under a Creative Commons Attribution 4.0 International License, which permits use, sharing, adaptation, distribution and reproduction in any medium or format, as long as you give appropriate credit to the original author(s) and the source, provide a link to the Creative Commons licence, and indicate if changes were made. The images or other third party material in this article are included in the article's Creative Commons licence, unless indicated otherwise in a credit line to the material. If material is not included in the article's Creative Commons licence and your intended use is not permitted by statutory regulation or exceeds the permitted use, you will need to obtain permission directly from the copyright holder. To view a copy of this licence, visit http://creativecommons.org/licenses/by/4.0/.

\section{References}

Adembri B, Cipriani L, Fantini F (2018) The maritime theatre at Hadrian's Villa and its decoration: analysis, interpretation, and integration of digital models. In: Inglese C, Ippolito A (eds) Conservation, Restoration, and analysis of architectural and archaeological heritage. IGI Global, Hershey, pp 225-255 
Apollonio FI, Gaiani M, Benedetti B (2012) 3D reality-based artefact models for the management of archaeological sites using 3D GIS: a framework starting from the case study of the Pompeii archaeological area. J Archaeol Sci 39(5):1271-1287. https://doi.org/10. 1016/j.jas.2011.12.034

Apollonio FI, Ballabeni M, Bertacchi S, Fallavollita F, Foschi R, Gaiani M (2018a) Digital documentation and restoration tools reusing existing imagery: a multipurpose model of the Neptune's Fountain in Bologna. Appl Geomat 10:295-316. https://doi.org/10.1007/ s12518-018-0210-x

Apollonio FI, Basilissi V, Callieri M, Dellepiane M, Gaiani M, Ponchio F, Rizzo F, Rubino AR, Scopigno R, Sobra G (2018b) A 3Dcentered information system for the documentation of a complex restoration intervention. J Cult Herit 29:89-99. https://doi.org/10. 1016/j.culher.2017.07.010

Apollonio FI, Gaiani M, Bertacchi S (2019) Managing cultural heritage with integrated services platform. Int Arch Photogramm Remote Sens Spat Inf Sci XLII-2(W11):91-98. https://doi.org/10.5194/ isprs-archives-XLII-2-W11-91-2019

Banfi F (2020) HBIM, 3D drawing and virtual reality for archaeological sites and ancient ruins. Virtual Archaeol Rev 11(23):16-33. https:// doi.org/10.4995/var.2020.12416

Bertacchi S, Al Jawarneh IM, Apollonio FI, Bertacchi G, Cancilla M, Foschini L, Grana C, Martuscelli G, Montanari R (2018) SACHER Project: A cloud platform and integrated services for cultural heritage and for restoration. In: Goodtechs'18 Proceedings of the 4th EAI International Conference on Smart Objects and Technologies for Social Good, pp 283-288. https://doi.org/10.1145/3284869. 3284871

Bitelli G, Balletti C, Brumana R, Barazzetti L, D’Urso MG, Rinaudo F, Tucci G (2019) The GAMHer research project for metric documentation of cultural heritage: current developments. Int Arch Photogramm Remote Sens Spat Inf Sci XLII-2/W11:239-246. https://doi.org/10.5194/isprs-archives-XLII-2-W11-239-2019

Breunig M, Bradley PE, Jahn M, Kuper P, Mazroob N, Rösch N, AlDoori M, Stefanakis E, Jadidi M (2020) Geospatial data management research: progress and future directions. ISPRS Int J Geo Inf 9(2):95. https://doi.org/10.3390/ijgi9020095

Campanaro DM, Landeschi G, Dell'Unto N, Touati AL (2016) 3D GIS for cultural heritage restoration: a "white box" workflow. J Cult Herit 18:321-332. https://doi.org/10.1016/j.culher.2015.09.006

Chiabrando F, Donato V, Lo Turco M, Santagati C (2018) Cultural heritage documentation, analysis and management using building information modelling: state of the art and perspectives. In: Ottaviano E, Pelliccio A, Gattulli V (eds) Mechatronics for Cultural heritage and civil engineering. Intelligent Systems, Control and Automation: Science and Engineering, 92. Springer, Cham, pp 181-202

Cipriani L, Fantini F (2018) Integration of pipelines and open issues in heritage digitisation. In: Remondino F, Georgopoulos A, GonzálezAguilera D, Agrafiotis P (eds) Latest developments in reality-based 3D surveying and modelling. MDPI, Basel (CH), pp 171-191. https://doi.org/10.3390/books978-3-03842-685-1-8

Cipriani L, Dresseno A, Agostini P, Fantini F (2018) Game engine per comunicare e valorizzare città e territorio: il progetto pilota "Chiuro, dal passato, il futuro". In: Salerno R (ed) Proceedings of the conference Rappresentazione/ Materiale/Immateriale - Quarantesimo Convegno Internazionale UID dei Docenti delle Discipline della Rappresentazione. Gangemi Editore International, Roma, pp $1035-1042$

Cohen J, Olano M, Manocha D (1998) Appearance-preserving simplification. In: SIGGRAPH '98: Proceedings of the $25^{\text {th }}$ annual conference on Computer graphics and interactive techniques, pp 115-122. https://doi.org/10.1145/280814.280832

Comunità Montana Valtellina di Sondrio (ed) (2010) Chiuro: itinerari tra storia ed arte. Comunità Montana Valtellina di Sondrio, Sondrio
Dore C, Murphy M (2017) Current state of the art historic building information modelling. Int Arch Photogramm Remote Sens Spat Inf Sci XLII-2(W5):185-192. https://doi.org/10.5194/isprs-archives-XLII2-W5-185-2017

Fernández-Palacios BJ, Morabito D, Remondino F (2017) Access to complex reality-based 3D models using virtual reality solutions. J Cult Herit 23:40-48. https://doi.org/10.1016/j.culher.2016.09.003

Gaiani M, Apollonio FI, Ballabeni A, Remondino F (2017) Securing color fidelity in 3D architectural heritage scenarios. Sensors 17(11):2437. https://doi.org/10.3390/s17112437

García-León J, Sánchez-Allegue P, Peña-Velasco C, Cipriani L, Fantini F (2018) Interactive dissemination of the 3D model of a baroque altarpiece: a pipeline from digital survey to game engines. SCIRES-it 8(2):59-76 dx.doi.org/10.2423/i22394303v8n2p59

Gonizzi Barsanti S, Malatesta SG, Lella F, Fanini B, Sala F, Dodero E, Petacco L (2018) The Winckelmann300 Project: dissemination of culture with virtual reality at the Capitoline Museum in Rome. Int Arch Photogramm Remote Sens Spat Inf Sci XLII-2:371-378. https://doi.org/10.5194/isprs-archives-XLII-2-371-2018

Grilli E, Remondino F (2019) Classification of 3D digital heritage. MDPI Remote Sens 11(7):847. https://doi.org/10.3390/rs1 1070847

Gröger G, Kolbe TH, Nagel C, Häfele K-H (2012) OpenGIS City Geography Markup Language (CityGML) Encoding Standard, Version 2.0.0. OGC Doc. No. 12-019, Open Geospatial Consortium. http://www.opengeospatial.org/standards/citygml. Accessed 20 October 2020

Guidi G, Angheleddu D (2016) Journal on Computing and Cultural Heritage 9. https://doi.org/10.1145/2843947

Ioannides M, Fink E, Brumana R, Patias P, Doulamis A, Martins J, Wallace M (eds) (2018) Digital Heritage. Progress in cultural heritage: documentation, preservation, and protection. EuroMed 2018, 7th International Conference, EuroMed 2018, Nicosia, Cyprus, October 29 - November 3, 2018, Proceedings, Part II, Lecture Notes in Computer Science, vol 11197. Springer, Cham. https:// doi.org/10.1007/978-3-030-01765-1

López FJ, Lerones PM, Llamas J, Gómez-García-Bermejo J, Zalama E (2018) A review of heritage building information modeling $(\mathrm{H}-$ BIM). Multimodal Technol Interact 2(2):21. https://doi.org/10. 3390/mti2020021

Matrone F, Colucci E, De Ruvo V, Lingua A, Spanò A (2019) HBIM in a semantic 3D GIS database. Int Arch Photogramm Remote Sens Spat Inf Sci XLII-2/W11:857-865. https://doi.org/10.5194/isprsarchives-XLII-2-W11-857-2019

Merlo A, Dalcò L, Fantini F (2012) Game engine for cultural heritage: new opportunities in the relation between simplified models and database. 18th International Conference on Virtual Systems and Multimedia. Milan 2012:623-628. https://doi.org/10.1109/VSMM. 2012.6365993

Messaoudi T, Véron P, Halina G, De Luca L (2018) An ontological model for the reality-based 3D annotation of heritage building conservation state. J Cult Herit 29:100-112. https://doi.org/10.1016/j. culher.2017.05.017

Monteforte F, Faccinelli E (eds) (1989) Chiuro: territorio, economia e storia di una comunità umana. Biblioteca Comunale "Luigi Faccinelli", Chiuro

Napolitano RK, Scherer G, Glisic B (2018) Virtual tours and informational modeling for conservation of cultural heritage sites. J Cult Herit 29:123-129. https://doi.org/10.1016/j.culher.2017.08.007

Ohori AK, Biljecki F, Diakité A, Krijnen T, Ledoux H, Stoter J (2017) Towards an integration of GIS and BIM data: what are the geometric and topological issues? ISPRS Ann Photogramm Remote Sens Spatial Inf Sci IV-4/W5:1-8. https://doi.org/10.5194/isprs-annalsIV-4-W5-1-2017

Pocobelli DP, Boehm J, Bryan P, Still J, Grau-Bové J (2018) BIM for heritage science: a review. Herit Sci 6:30. https://doi.org/10.1186/ s40494-018-0191-4 
Poux F, Neuville R, Billen R (2017) Point cloud classification of tesserae from terrestrial laser data combined with dense image matching for archaeological information extraction. Int Arch Photogramm Remote Sens Spat Inf Sci IV-2(W2):203-211. https://doi.org/10. 5194/isprs-annals-IV-2-W2-203-2017

Remondino F, Gaiani M, Apollonio F, Ballabeni A, Ballabeni M, Morabito D (2016) 3D documentation of 40 kilometers of historical porticoes-the challenge. Int Arch Photogramm Remote Sens Spat Inf Sci XLI-B5:711-718. https://doi.org/10.5194/isprs-archivesXLI-B5-711-2016

Remondino F, Georgopoulos A, González-Aguilera D, Agrafiotis P (eds) (2018) Latest developments in reality-based 3D surveying and modelling. MDPI, Basel. https://doi.org/10.3390/books978-303842-685-1-8

Rushmeier HE (2001) 3D Capture for Computer Graphics. In: Proceedings Third International Conference on 3-D Digital Imaging and Modeling, Quebec City, Quebec, Canada, pp 375381. https://doi.org/10.1109/IM.2001.924481

Scopigno R, Dellepiane M (2017) Integration and analysis of sampled data: visualization approaches and platforms. In: Masini N,
Soldovieri F (eds) Sensing the Past. Geotechnologies and the Environment, 16. Springer, Cham, pp 377-393. https://doi.org/10. 1007/978-3-319-50518-3 18

Soler F, Melero F, Luzón M (2017) A complete 3D information system for cultural heritage documentation. J Cult Herit 23:49-57. https:// doi.org/10.1016/j.culher.2016.09.008

Thompson EM, Biasotti S, Sorrentino G, Polig M, Hermon S (2018) Towards an automatic 3D patterns classification: the GRAVITATE use case. In: Sablatnig R, Wimmer M (eds) Eurographics Workshop on Graphics and Cultural Heritage. The Eurographics Association. https://doi.org/10.2312/gch.20181372

von Schwerin J, Richards-Rissetto H, Remondino F, Agugiaro G, Girardi G (2013) The MayaArch3D project: A 3D WebGIS for analyzing ancient architecture and landscapes. Lit Ling Comput 28(4):736753. https://doi.org/10.1093/llc/fqt059

Wang Z, Shi W, Akoglu K, Kotoula E, Yang Y, Rushmeier HE (2018) CHER-Ob: a tool for shared analysis and video dissemination. ACM J Comput Cult Herit 11(4):1-22. https://doi.org/10.1145/3230673 